\title{
High total volatile organic compounds pollution in a hospital dental department
}

\author{
Ming-Hui Liu • Tao-Hsin Tung • Fen-Fang Chung • \\ Li-Chuan Chuang • Gwo-Hwa Wan
}

Received: 13 June 2017 / Accepted: 28 September 2017 / Published online: 18 October 2017

(C) The Author(s) 2017. This article is an open access publication

\begin{abstract}
Bioaerosols produced by dental procedures may affect indoor air quality and cause infections in dental healthcare workers. To provide air quality data that can be used to protect dental healthcare workers, this study evaluated the air quality and its influencing
\end{abstract}

\author{
M.-H. Liu \\ Department of Pediatric Dentistry, Taoyuan Chang Gung \\ Memorial Hospital, Taoyuan, Taiwan, Republic of China \\ e-mail: pedomhliu2@gmail.com \\ T.-H. Tung \\ Department of Medical Research and Education, Cheng-Hsin \\ General Hospital, Taipei, Taiwan, Republic of China \\ e-mail: ch2876@gmail.com \\ F.-F. Chung \\ Department of Nursing, Chang Gung University of Science and \\ Technology, Taoyuan, Taiwan, Republic of China \\ e-mail: fenfang.chung@gmail.com

\section{L.-C. Chuang} \\ Department of Pediatric Dentistry, Linkuo Chang Gung Memorial \\ Hospital, Taoyuan, Taiwan, Republic of China \\ e-mail: soleus34@cgmh.org.tw

\section{G.-H. Wan} \\ Department of Respiratory Therapy, College of Medicine, Chang \\ Gung University, Taoyuan, Taiwan, Republic of China \\ G.-H. Wan $(\bowtie)$ \\ Department of Respiratory Therapy, Chang Gung University of \\ Science and Technology, Chiayi, Taiwan, Republic of China \\ e-mail: ghwan@mail.cgu.edu.tw
}

G.-H. Wan

Department of Neurosurgery, Linkou Chang Gung Memorial Hospital, Taoyuan, Taiwan, Republic of China factors in the dental department of the Chang Gung Memorial Hospital in Taiwan. The study was a crosssectional study design. Indoor air quality (IAQ) evaluations were conducted in six locations: pediatric dentistry, craniofacial orthodontic dentistry, periodontal dentistry, and general practice dentistry, instrument washing room, and patient waiting area. The measured air quality parameters included temperature, relative humidity, and concentrations of $\mathrm{CO}_{2}$, total volatile organic compounds (TVOCs), suspended particulate matter (PM), and bacteria. TVOCs concentrations at all six sampling stations were found to exceed the indoor air quality standards prescribed by the Taiwan Environmental Protection Agency. The highest concentrations of atmospheric $\mathrm{PM}_{10}, \mathrm{PM}_{2.5}$, and $\mathrm{PM}_{1}$ were found in the periodontal dentistry department, while the lowest concentrations occurred in the patient waiting area. The detection rate for Gram-positive bacteria was highest in the pediatric department $(25 \%)$ and lowest in the instrument washing room (9\%). Micrococcus luteus and Bacillus cereus were the primary pathogens detected. The dental departments of the hospital had a serious TVOCs pollution. The air quality of dental departments deserves long-term surveillance and attention.

Keywords Indoor air quality . Dental department . Particulate matter $\cdot$ Volatile organic compounds $\cdot$ Bacteria

\section{Introduction}

Dental treatments include many diverse procedures, such as restorative dentistry, root canal therapy, ultrasonic 
scaling, periodontal curettage of dental calculus, periodontal surgery, prosthetic dentistry, orthodontic treatment, surgical extraction of impacted third molars, and dental implant surgery. The use of high-speed drills or ultrasonic scalers can produce aerosols. Microbial aerosols and splatters are also generated during dental procedures. These aerosols are air-suspended liquid or solid molecules that contain bacteria, viruses, fungi, saliva, and blood. Aerosols produced during dental procedures not only reduce the IAQ, but also pose a threat to the health of dental staff and are important sources of infection (Szymańska 2007; Bennett et al. 2000; Leggat et al. 2007).

IAQ assessment indicators include concentrations of $\mathrm{CO}_{2}$ (Li et al. 2001; Scheff et al. 2000), PM, TVOCs, bacteria (Liu et al. 2000), fungi, and viruses, as well as temperature and relative humidity (RH). Particle concentrations in the indoor air of a hospital are related to human activity, air exchange, and air filtration (Streifel et al. 1989). High concentrations of aerosols can be produced by a high-speed drill or rotating instrument used inside an oral cavity (Harrel and Molinari 2004; Kedjarune et al. 2000; Leggat and Kedjarune 2001). The composition, concentration, and distribution of aerosols is affected by factors such as the type of treatment procedure, size and location of the treatment room, duration of treatment, mode of treatment, patient characteristics, and seasonality (Bennett et al. 2000; Kedjarune et al. 2000; Grenier 1995).

In one study, closed and isolation dental clinic rooms had high bacterial concentrations $\left((216 \pm 75) \mathrm{CFU} \mathrm{m}^{-3}\right.$ during scaling and $(75 \pm 22) \mathrm{CFU} \mathrm{m}^{-3}$ during fillings). The bacterial concentration after $2 \mathrm{~h}$ of dental treatment in the isolation dental treatment room was the same as the background concentration of $12-14 \mathrm{CFU} \mathrm{m}^{-3}$ (Grenier 1995). In the same study, bacteria were detectable in all areas of an open clinic with multiple dental chairs. Peak bacterial concentrations were observed in the main treatment area after $3 \mathrm{~h}$ of dental treatment (76$114 \mathrm{CFU} \mathrm{m}^{-3}$ ), and the amount of bacteria in the nontreatment area $\left(42 \mathrm{CFU} \mathrm{m}^{-3}\right.$ ) remained higher than the background level. This shows that aerosols can spread and move through the air (Grenier 1995). All dental procedures, and particularly dental surgery, are intended to be performed in a sterile environment. The use of protective measures, such as sterile gloves, gowns, and face masks, is very important during these procedures.

The climate in Taiwan is characterized by high temperature and humidity, which are very conducive to the formation of bioaerosols. Patients, family members, and healthcare workers are the main sources of biological aerosols in hospitals. The close contact between patients and medical staff, coupled with the central airconditioning systems typically used in hospitals, increases the probability of mutual infection. To date, few studies have evaluated the IAQ of dental departments in hospitals. The purpose of this study was to investigate the air quality parameters and aerosol distribution in six different locations of the dental department: pediatric dentistry, craniofacial orthodontic dentistry, periodontal dentistry, general practice dentistry, instrument washing room, and patient waiting area.

\section{Materials and methods}

\section{Sampling locations}

Permits for this study were obtained from the Taoyuan Chang Gung Memorial Hospital in northern Taiwan. This study evaluated the IAQ for the six locations of the dental department, including pediatric dentistry (PEDI), craniofacial orthodontic dentistry (ORTHO), periodontal dentistry (PERIO), general practice dentistry (GP), the instrument washing room (IR), and the patient waiting area (PWA).

Figure 1 shows the six dental departments of the selected hospital. The space volumes of PEDI, PERIO, IR, ORTHO, GP, and PWA were 26.51, 39.22, 31.05, $96.59,232.03$, and $78.62 \mathrm{~m}^{3}$, respectively. During the sampling period, indoor air was conditioned but not heated.

Air quality monitoring

This study was performed from July to August in 2016. Indoor air quality parameters of six locations in the dental department were monitored for $9 \mathrm{~h}$ (8 am to 5 pm) per day for 3 days. Bacterial samples were collected twice a day (in the morning and in the afternoon) for 3 days. The air sampling instruments were placed approximately $1.5 \mathrm{~m}$ from the dental unit to avoid interrupting dental treatment, and as close to the center of the sampling area as possible. All instruments were positioned $1 \mathrm{~m}$ above the floor to simulate the seated breathing zone of healthcare workers.

The evaluated air quality indices included the air temperature, $\mathrm{RH}$, and concentrations of TVOCs, $\mathrm{CO}_{2}$, suspended PM, and bacteria. The air temperature, $\mathrm{RH}$, 
(a) Pediatric dentistry room

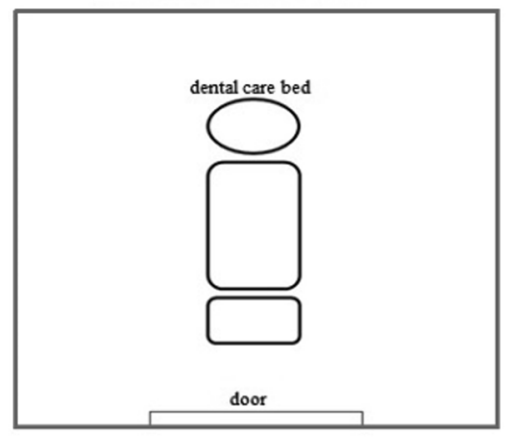

(d) General practice dentistry area

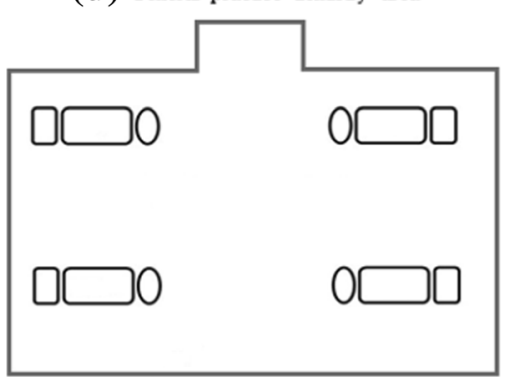

(b)

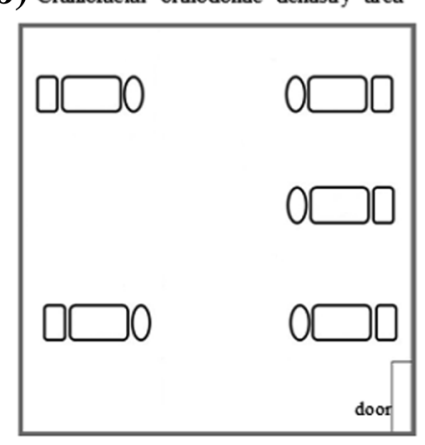

(e) Instrument washing room

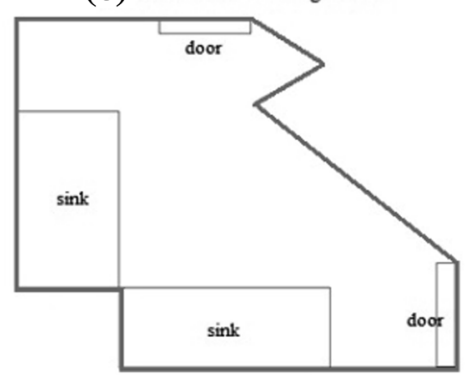

(c) Periodontal dentistry room

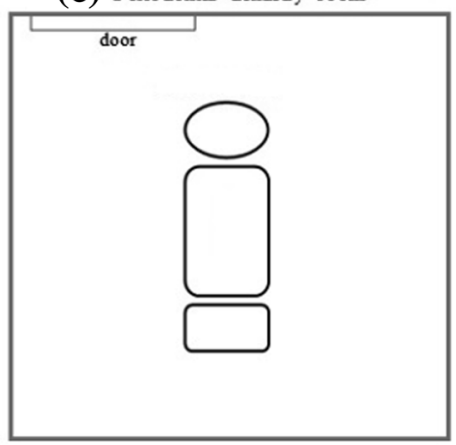

(f) Patient waiting area

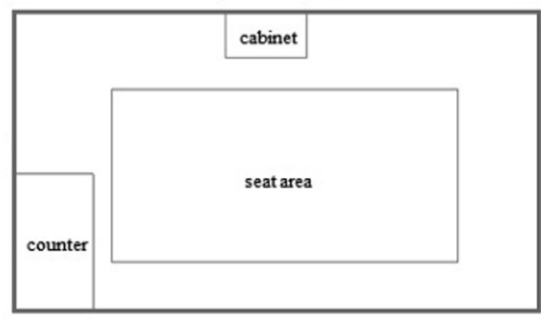

Fig. 1 Diagram of the six locations of the dental department

and $\mathrm{CO}_{2}$ concentration were determined every minute using a digital psychrometer (TSI, Inc., Shoreview, MN, USA). The PM levels were measured every $6 \mathrm{~s}$ using a portable dust monitor with 31 size channels measured the size range between 0.25 and $32 \mu \mathrm{m}$ (Model 1.110; Grimm Labortechnik Ltd., Ainring, Germany). The level of TVOCs was determined every minute by a hand carried detector (ppb RAE 30000, USA). Bacterial concentrations were assessed using Andersen one-stage viable impactors (N6; Andersen Samplers, Atlanta, Georgia) with $20 \mathrm{~mL}$ of tryptic soy agar at an airflow rate of 28.3 $\mathrm{L} \mathrm{min}^{-1}$ for $3 \mathrm{~min}$. Duplicate bacterial samples were collected to ensure sampling accuracy, and bacterial samples were incubated at $30 \pm 1{ }^{\circ} \mathrm{C}$ for $48 \pm 2 \mathrm{~h}$, as recommended by the Taiwan Environmental Protection Agency (TEPA). The positive hole conversion table and sampled air volume were used to calculate the number of colony forming units per volume of air $\left(\mathrm{CFU} \mathrm{m}{ }^{-3}\right)$. All the bacterial colonies were identified biochemically.

\section{Statistical analysis}

Data were analyzed using SPSS version 21.0 (IBM Corp., Armonk, NY, USA). All figures were constructed with GraphPad Prism version 6.0 (GraphPad Software, San Diego, CA, USA). The two-sided $p$ value with $\alpha<0.05$ was considered statistically significant. Besides the bacterial concentration, the hourly data of air quality indices were used for statistical analysis in the study. The $\mathrm{PM}$ was classified as $\mathrm{PM}_{10}$ (aerodynamic diameter $\leq 10 \mu \mathrm{m}$ ), $\mathrm{PM}_{2.5}$ (aerodynamic diameter $\leq 2.5 \mu \mathrm{m}$ ), and $\mathrm{PM}_{1}$ (aerodynamic diameter $\leq 1 \mu \mathrm{m}$ ). The IAQ indices in the six locations of the dental department in the hospital were compared using the one-way analysis of variance test with Scheffe's post hoc comparison or Kruskal-Wallis test for continuous variables. Pearson correlation analysis was applied to identify the relationship between combinations of two continuous variables with normally distributed data.

\section{Results}

During the study period, the largest and smallest numbers of people were observed in ORTHO $(N=105)$ and in PERIO $(N=66)$, respectively. Air quality data collected from the six locations of the dental department $(n=156)$ is shown in Table 1 . The highest temperature was recorded in PEDI $\left(24.5^{\circ} \mathrm{C}\right)$, while the lowest was recorded in ORTHO $\left(20.43{ }^{\circ} \mathrm{C}\right)$. The temperature differences in the six locations are statistically significant $(p<0.001)$. The IR had the highest RH value $(70.59 \%)$, 
while PERIO had the lowest RH value $(58.11 \%)$. Differences in the $\mathrm{RH}$ values in the six locations were statistically significant $(p<0.001)$. The measured $\mathrm{CO}_{2}$ concentrations in six regions ranged from 491.73 to $653.65 \mathrm{ppm}$, with the maximum occurring in PERIO and the minimum occurring in IR. A significant difference $(p<0.001)$ was found in the $\mathrm{CO}_{2}$ concentrations for the six locations, but all values were within the TEPA indoor air quality standard of $1000 \mathrm{ppm}$.

The average TVOCs concentrations found in the six sampling locations all exceeded TEPA indoor air quality standards of $560 \mathrm{ppb} \mathrm{h}^{-1}$. The highest concentration occurred in GP (1373.99 ppb) and the lowest occurred in the IR $(674.56 \mathrm{ppb})$. The TVOC concentrations in the six locations were significantly different $(p<0.001)$. The maximum concentrations of $\mathrm{PM}_{10}, \mathrm{PM}_{2.5}$, and $\mathrm{PM}_{1}$ were found in PERIO, while the minimum concentrations were found in the PWA. Concentrations of $\mathrm{PM}_{10}, \mathrm{PM}_{2.5}$, and $\mathrm{PM}_{1}$ had statistically significant differences between the six sampling locations $(p<0.001)$. However, none of the values exceeded the TEPA standard. The upper limit for the $\mathrm{PM}_{10}$ concentration was $75 \mu \mathrm{g} \mathrm{m}^{-3}$ for 24-h average concentration, while that for $\mathrm{PM}_{2.5}$ was $35 \mu \mathrm{g} \mathrm{m}^{-3}$ for 24 -h average concentration.

The median concentrations of airborne bacteria in PERIO (773.01 CFU m ${ }^{-3}$ ), GP (307.56 $\mathrm{CFU} \mathrm{m}^{-3}$ ), IR (619.63 $\mathrm{CFU} \mathrm{m}^{-3}$ ), and PWA (1299.25 $\mathrm{CFU} \mathrm{m}^{-3}$ ) were significantly higher than those in ORTHO (84.48 $\mathrm{CFU} \mathrm{m}^{-3}$ ) and PEDI (247.97 CFU m ${ }^{-3}$ ). Also, a significant difference in the airborne bacterial concentration was found between PWA and IR $(p=0.025)$. In this study, the bacterial concentrations were generally lower than the TEPA indoor air quality standards, which sets an

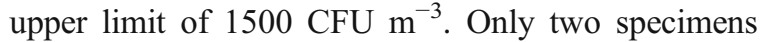
exceeded the $1500 \mathrm{CFU} \mathrm{\textrm {m } ^ { - 3 }}$ standard, both during afternoon sessions, one in GP $\left(4058.67 \mathrm{CFU} \mathrm{m}^{-3}\right)$ and one in the PWA (2551.39 $\mathrm{CFU} \mathrm{m}^{-3}$ ) (data not shown). In the morning and afternoon sessions in PEDI and ORTHO,

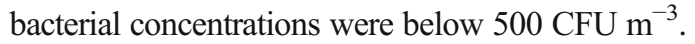

Temperature had a significant negative correlation with RH $(r=-0.463, p<0.01)$ and TVOCs $(r=-0.16, p<0.05)$, while RH had a significant negative correlation with $\mathrm{CO}_{2}(r=-0.550, p<0.01)$ and TVOC $(r=-0.172, p<0.05)$ concentrations (Table 2). In addition, $\mathrm{CO}_{2}$ concentration was positively correlated with the concentration of TVOCs $(r=0.377, p<0.01)$, $\mathrm{PM}_{10}(r=0.28, p<0.01)$, and $\mathrm{PM}_{2.5}(r=0.16, p<0.05)$. $\mathrm{PM}_{10}$ had significant positive correlations with $\mathrm{PM}_{2.5}$ $(r=0.827, p<0.01)$ and $\mathrm{PM}_{1}(r=0.739, p<0.01)$. 
Table 2 Associations of air quality indices in the six dental departments

(1)

(2)

$$
1
$$

(1) Temperature

(2) $\mathrm{RH}$

$-0.463^{*}$

(3) $\mathrm{CO}_{2}$

(4) TVOCs

$-0.008$

(5) $\mathrm{PM}_{10}$

(6) $\mathrm{PM}_{2.5}$

-0.160 *

0.013

$-0.110$

(7) $\mathrm{PM}_{1}$

$-0.126$

(8) Bacteria

0.194

(9) Number of people

0.087
(3) (4)

(5)

(6)

(7)

(8)

(9)

$* p<0.05, * * p<0.01$

The types and isolation rates of bacteria in the six dental departments are listed in Table 3. The total airborne bacteria species include both Gram-positive and Gram-negative bacteria. Most of the bacteria were Gram-positive species (94\%). The proportion of Grampositive bacteria was largest in PEDI (25\%) and smallest in the IR (9\%). The Gram-positive bacteria included Micrococcus luteus (31\%), Bacillus cereus (22\%),
Bacillus circulans (9\%), other Bacillus spp. (6\%), Micrococcus lylae (6\%), other Micrococcus spp. (6\%), Achromobacter spp. (3\%), Bacillus licheniformis (3\%), Staphylococcus haemolyticus (3\%), and Staphylococcus kloosii (3\%). Gram-negative bacteria, which included Brevundimonas diminuta and Nocardia spp., were only found in GP and represented a mere $6 \%$ of the population.

Table 3 Isolation rates of airborne bacteria (\%) in the six dental departments

\begin{tabular}{|c|c|c|c|c|c|c|c|}
\hline \multirow[t]{2}{*}{ Airborne bacterial species } & \multicolumn{7}{|l|}{ Isolation rate $^{\dagger}$} \\
\hline & Total & PEDI & ORTHO & PERIO & GP & IR & PWA \\
\hline Gram-positive bacteria & $30 / 32(94 \%)$ & $8(25 \%)$ & $6(19 \%)$ & $4(13 \%)$ & $5(16 \%)$ & $3(9 \%)$ & $4(13 \%)$ \\
\hline Achromobacter species & $1 / 32(3 \%)$ & $0(0 \%)$ & $1(3 \%)$ & $0(0 \%)$ & $0(0 \%)$ & $0(0 \%)$ & $0(0 \%)$ \\
\hline Bacillus cereus & $7 / 32(22 \%)$ & $5(16 \%)$ & $1(3 \%)$ & $0(0 \%)$ & $0(0 \%)$ & $1(3 \%)$ & $0(0 \%)$ \\
\hline Bacillus circulans & $3 / 32(9 \%)$ & $1(3 \%)$ & $0(0 \%)$ & $0(0 \%)$ & $1(3 \%)$ & $0(0 \%)$ & $1(3 \%)$ \\
\hline Bacillus licheniformis & $1 / 32(3 \%)$ & $0(0 \%)$ & $0(0 \%)$ & $1(3 \%)$ & $0(0 \%)$ & $0(0 \%)$ & $0(0 \%)$ \\
\hline Bacillus species & $2 / 32(6 \%)$ & $0(0 \%)$ & $1(3 \%)$ & $1(3 \%)$ & $0(0 \%)$ & $0(0 \%)$ & $0(0 \%)$ \\
\hline Micrococcus luteus & $10 / 32(31 \%)$ & $2(6 \%)$ & $2(6 \%)$ & $1(3 \%)$ & $2(6 \%)$ & $1(3 \%)$ & $2(6 \%)$ \\
\hline Micrococcus lylae & $2 / 32(6 \%)$ & $0(0 \%)$ & $0(0 \%)$ & $1(3 \%)$ & $1(3 \%)$ & $0(0 \%)$ & $0(0 \%)$ \\
\hline Micrococcus species & $2 / 32(6 \%)$ & $0(0 \%)$ & $0(0 \%)$ & $0(0 \%)$ & $0(0 \%)$ & $1(3 \%)$ & $1(3 \%)$ \\
\hline Staphylococcus haemolyticus & $1 / 32(3 \%)$ & $0(0 \%)$ & $0(0 \%)$ & $0(0 \%)$ & $1(3 \%)$ & $0(0 \%)$ & $0(0 \%)$ \\
\hline Staphylococcus kloosii & $1 / 32(3 \%)$ & $0(0 \%)$ & $1(3 \%)$ & $0(0 \%)$ & $0(0 \%)$ & $0(0 \%)$ & $0(0 \%)$ \\
\hline Gram-negative bacteria & $2 / 32(6 \%)$ & $0(0 \%)$ & $0(0 \%)$ & $0(0 \%)$ & $2(6 \%)$ & $0(0 \%)$ & $0(0 \%)$ \\
\hline Brevundimonas diminuta & $1 / 32(3 \%)$ & $0(0 \%)$ & $0(0 \%)$ & $0(0 \%)$ & $1(3 \%)$ & $0(0 \%)$ & $0(0 \%)$ \\
\hline Nocardia spp. & $1 / 32(3 \%)$ & $0(0 \%)$ & $0(0 \%)$ & $0(0 \%)$ & $1(3 \%)$ & $0(0 \%)$ & $0(0 \%)$ \\
\hline
\end{tabular}

PEDI pediatric dentistry, ORTHO craniofacial orthodontic dentistry, PERIO periodontal dentistry, GP general practice dentistry, IR instrument washing room, $P W R$ patient waiting area

${ }^{\dagger}$ The number of specific isolated microorganism divided by the total number of isolated microorganisms 


\section{Discussion}

Hospital indoor air pollution is associated with inadequate building environments, including building materials, air-conditioning systems, and ventilation rates, and with human factors, such as overcrowding in constrained spaces. This was the first study in Taiwan evaluating air quality indices for a dental department in a hospital.

Dentists face potential exposure to various air pollutants during different types of dental procedures. Studies have shown that dental workers have a higher chance of exposure to microbes and, consequently, a higher risk of respiratory infections, inflammation, and disease than do other workers (Bennett et al. 2000). In addition, skin irritation and eye infections are often a health hazard for dental staff (Leggat et al. 2007). The distance between the dentist and the patient, the location of the patient, and the patient head height during dental treatment also affected the distribution and concentration of aerosols. Studies have shown that the central location of a dentist's face (including the eyes and nasal region) are at high-risk for infection (Nejatidanesh et al. 2013). Dental rubber barriers used in mouth during patient treatment can effectively reduce aerosol concentrations (Pina-Vaz et al. 2008; Al-Amad et al. 2016; Tag and El-Hady 1997), while patients using antibacterial mouthwash before dental treatment also proved to decrease aerosolized bacterial production effectively (Fine et al. 1992; Molinari and Molinari 1992; Fine et al. 1993).

In our study, the TVOCs concentrations of the six sampling locations exceeded the TEPA indoor air quality standard, and the highest TVOCs concentration was found in GP. Resin materials are often used for temporary prosthetics and relining removable dentures in this department. One of the main components of resin monomer is methyl methacrylate, which has a strong acrid smell and volatile character. The resin monomer spreads through the air following polymerization and incomplete setting. This monomer is the main source of volatile organic compounds in GP, which has an open area floor plan with five dentists working simultaneously. The partial pressure of resin monomer vapor is thus very high from the volatile gas accumulation in this location.

The second highest value of TVOCs was recorded in PERIO, which is a closed treatment room. Common treatments here include ultrasonic scaling, periodontal surgery, and dental implant surgery, none of which include volatile materials. However, 3 days a week, there are four prosthetic dentists who treat patients in this department. They often use resin monomers to make temporary prosthetics and adjust dentures. The volatile gas therefore spreads through the airconditioning system. In addition, every Wednesday afternoon, the nurses use bleaching solvent to disinfect the boxes used for collecting surgery devices, and they throw away the bleach the following day. We speculate that the resin monomer and the bleaching solvent both contributed to PERIO having the second highest concentration of TVOCs. In ORTHO, the dentists also use resin materials to reline newborn cleft palates. In addition, orthodontic and pediatric dentists often use resinbased adhesive materials and bonding agents, which have volatile properties. The lowest concentration of TVOCs occurred in the IR because only enzyme powder is used to soak and clean all instruments, so no volatile material sources were found in this location.

In order to prevent the formation of TVOCs in dental departments, high-power ventilation can be used along with a high-density charcoal filter system near the dentistry procedure locations. A method for preventing high TVOC concentrations during dental treatment is still needed. One suggestion is that all dentists should close the button of resin monomer immediately after using it. The correct powder to liquid ratio would also help prevent unnecessary emissions. High values of TVOCs are harmful to the working staff and patients. Hospitals need to focus more on improving the air quality in their dental departments. Additionally, $\mathrm{CO}_{2}$ levels are closely related to TVOC, $\mathrm{PM}_{10}$, and $\mathrm{PM}_{2.5}$ concentrations. With a better ventilation system, the $\mathrm{CO}_{2}$ level is decreased, and the volatile solvents and aerosols would be more effectively flushed and filtered out.

Dental scaling can produce high concentrations of aerosols, which can be removed using high-intensity evacuators (Barnes et al. 1998; Harrel et al. 1996; Harrel et al. 1998). High-intensity suction is thus a good way to reduce the risk of exposure to microbes. Bioaerosols collected in the dental locations included Streptococcus mutans and Streptococcus sanguinis bacteria, mainly from the patient mouths (Earnest and Loesche 1991), as well as fungi from the environment (Krogulski and Szczotko 2010). Adding a fluorescent agent to the water column of a high-speed drill would indicate when splashing has occurred on the head, upper arm, neck, or chest of the dentist, which is a problem especially when treating the lower right molar area. Most of the sputtering landed on the patient chest 
(Bentley et al. 1994). In this study, we found bacterial counts as high as $4000 \mathrm{CFU} \mathrm{m}^{-3}$ in GP one afternoon. Because the number of patients that day was up to 20 people simultaneously, the airborne bacterial level was particularly high. For each afternoon session in the PWA, a higher bacterial concentration was noted, possibly because more patients and families were present. During afternoon sessions in PEDI and ORTHO, bacterial concentrations were all below $500 \mathrm{CFU} \mathrm{m}^{-3}$. We infer that this was because of a lower number of patients on weekdays. There were many airborne bacterial species in PEDI and ORTHO, due to the larger number of people and children present.

In conclusion, serious TVOCs pollution was found in the dental departments of the hospital. The air quality of dental departments deserves attention and requires longterm surveillance from environmental safety and health departments in hospitals to protect patients as well as dentists and other nursing workers. The distributions of air pollutant concentrations during common dental treatment procedures should be evaluated in a future study.

Acknowledgements The authors thank Chang Gung Memorial Hospital in Taiwan for financially supporting this research under contract nos. BMRP441 and CMRPG5F0171.

\section{Compliance with ethical standards}

Conflict of interest The authors declare that they have no conflict of interest.

\begin{abstract}
Abbreviations TVOCs, total volatile organic compounds; PM, suspended particulate matter; RH, relative humidity; PEDI, pediatric dentistry; ORTHO, craniofacial orthodontic dentistry; PERIO, periodontal dentistry; GP, general practice dentistry; IR, instrument washing room; PWA, patient waiting area; TEPA, Taiwan Environmental Protection Agency

Open Access This article is distributed under the terms of the Creative Commons Attribution 4.0 International License (http:// creativecommons.org/licenses/by/4.0/), which permits unrestricted use, distribution, and reproduction in any medium, provided you give appropriate credit to the original author(s) and the source, provide a link to the Creative Commons license, and indicate if changes were made.
\end{abstract}

\section{References}

Al-Amad, S. H., Awad, M. A., Edher, F. M., Shahramian, K., \& Omran, T. A. (2016). The effect of rubber dam on atmospheric bacterial aerosols during restorative dentistry. Journal of Infection and Public Health, S1876-0341(16), 30032-30036.
Barnes, J. B., Harrel, S. K., \& Rivera-Hidalgo, F. (1998). Blood contamination of the aerosols produced by in vivo use of ultrasonic scalers. Journal of Periodontology, 69, 434-438.

Bennett, A. M., Fulford, M. R., Walker, J. T., Bradshaw, D. J., Martin, M. V., \& Marsh, P. D. (2000). Microbial aerosols in general dental practice. British Dental Journal, 189, 664-667.

Bentley, C. D., Burkhart, N. W., \& Crawford, J. J. (1994). Evaluating spatter and aerosol contamination during dental procedures. Journal of the American Dental Association, 125, 579-584.

Earnest, R., \& Loesche, W. (1991). Measuring harmful levels of bacteria in dental aerosols. Journal of the American Dental Association, 122, 55-57.

Fine, D. H., Mendieta, C., Barnett, M. L., Furgang, D., Meyers, R., Olshan, A., \& Vincent, J. (1992). Efficacy of pre-procedural rinsing with an antiseptic in reducing viable bacteria in dental aerosols. Journal of Periodontology, 63, 821-824.

Fine, D. H., Yip, J., Furgang, D., Barnett, M. L., Olshan, A. M., \& Vincent, J. (1993). Reducing bacteria in dental aerosols: preprocedural use of an antiseptic mouth rinse. Journal of the American Dental Association, 124, 56-58.

Grenier, D. (1995). Quantitative analysis of bacterial aerosols in two different dental clinic environments. Applied and Environmental Microbiology, 61, 3165-3168.

Harrel, S. K., \& Molinari, J. (2004). Aerosols and splatter in dentistry: a brief review of the literature and infection control implications. Journal of the American Dental Association, 135, 429-437.

Harrel, S. K., Barnes, J. B., \& Rivera-Hidalgo, F. (1996). Reduction of aerosols produced by ultrasonic scalers. Journal of Periodontology, 67, 28-32.

Harrel, S. K., Barnes, J. B., \& Rivera-Hidalgo, F. (1998). Aerosol and splatter contamination from the operative site during ultrasonic scaling. Applied and Environmental Microbiology, 129, 1241-1249.

Kedjarune, U., Kukiattrakoon, B., Yapong, B., Chowanadisai, S., \& Leggat, P. (2000). Bacterial aerosols in the dental clinic: effect of time, position and type of treatment. International Dental Journal, 50, 103-107.

Krogulski, A., \& Szczotko, M. (2010). Microbiological quality of indoor air in dentist's offices. Roczniki Państwowego Zakładu Higieny, 61, 99-102.

Leggat, P. A., \& Kedjarune, U. (2001). Bacterial aerosols in the dental clinic: a review. International Dental Journal, 51, 39-44.

Leggat, P. A., Kedjarune, U., \& Smith, D. R. (2007). Occupational health problems in modern dentistry: a review. Industrial Health, 45, 611-621.

Li, W. M., Lee, S. C., \& Chan, L. Y. (2001). Indoor air quality at nine shopping malls in Hong Kong. Science of the Total Environment, 273, 27-40.

Liu, L. J., Krahmer, M., Fox, A., Feigley, C. E., Featherstone, A., Saraf, A., \& Larsson, L. (2000). Investigation of the concentration of bacteria and their cell envelope components in indoor air in two elementary schools. Journal of the Air \& Waste Management Association, 50, 1957-1967.

Molinari, J. A., \& Molinari, G. E. (1992). Is mouth rinsing before dental procedures worthwhile? Journal of the American Dental Association, 123, 75-80.

Nejatidanesh, F., Khosravi, Z., Goroohi, H., Badrian, H., \& Savabi, O. (2013). Risk of contamination of different areas 
of dentist's face during dental practices. International Journal of Preventive Medicine, 4, 611-615.

Pina-Vaz, I., Pina-Vaz, C., Carvalho, M. F., \& Azevedo, A. (2008). Evaluating spatter and aerosol contamination during opening of access cavities in endodontics. Revista de Clínica $e$ Pesquisa Odontológica, 4, 77-83.

Scheff, P. A., Paulius, V. K., Huang, S. W., \& Conroy, L. M. (2000). Indoor air quality in a middle school, Part I: Use of $\mathrm{CO} 2$ as a tracer for effective ventilation. Applied Occupational and Environmental Hygiene, 5, 824-834.
Streifel, A. J., Vesley, D., Rhame, F. S., \& Murray, B. (1989). Control of airborne fungal spores in a university hospital. Environment International, 15, 221-227.

Szymańska, J. (2007). Dental bioaerosol as an occupational hazard in a dentist's workplace. Annals of Agricultural and Environmental Medicine, 14, 203-207.

Tag El-Din, A. M., \& El-Hady Ghoname, N. A. (1997). Efficacy of rubber dam isolation as an infection control procedure in paediatric dentistry. Eastern Mediterranean Health Journal, 3, 530-539. 